\title{
Teacher Perceptions of Screening and Mental Health Practices Survey: A Validation Study
}

\author{
Alyssa Faye Clare, Sara A. Cornett, Kathryn M. Trainor, \& Joni Williams \\ Splett \\ University of Florida
}

Faculty Mentor: Joni Williams Splett, School of Special Education, School Psychology \& Early

Childhood Studies

\begin{abstract}
Universal screening in schools has been widely recommended to improve identification of social, emotional, and behavioral concerns and access to services, but it requires quality implementation to meaningfully reduce children's large unmet mental health need. Implementation quality is affected by macro, school, and individual level determinants. The Teacher Perceptions of Screening and Mental Health Practices Survey (TPSMHPS) was developed to assess determinants at the school and individual (i.e., educator) level, including each school's organizational climate and teachers' perceptions of how acceptable universal screening and their school's utilization of it was. Data analyses were run in this validity study to measure the survey's preliminary psychometric properties. The internal reliability of the survey was indicated moderate to high reliability (Cronbach's alpha $=0.787$ ). One-way ANOVAs examined the survey's sensitivity to differences between schools on four subscales, including acceptability of individual-level acceptability of interventions and screening, as well as school organizational-level of intervention resource management and acceptability. Results indicate that the TPSMHPS survey and four subscales used in the current study are internally consistent, however statistically significant between school differences were not detected.

Keywords: screening, implementation, interventions, emotional and behavioral disorders
\end{abstract}

\section{Introduction}

Students with social, emotional, and behavioral (SEB) concerns often struggle academically and present disruptions in the classroom (Darney et al., 2013). An estimated 10\% to $25 \%$ of young children develop a SEB problem severe enough to impact their education and relationships (Forness et al., 2012). Many students who need help do not all receive the resources that they need (Merikangas et al., 2011). Poorer outcomes are consistently seen as children mature past the school age. For example, children with emotional behavioral disorders experience lower rates of graduation from secondary schools, higher rates of arrest, lack of achievement in future occupations, and unsuccessful integration into society (Darney et al., 2013). 


\section{Need for Screening and Intervention in Schools}

Schools have become a primary location for service delivery due to the amount of time students spend there. Despite evidence indicating the number of students who experience SEB problems while in school, there is still a gap between identification of need and delivery of services (Splett et al., 2018). Of all the children who require resources to support their SEB needs for externalizing behaviors, only a third of students receive interventions (Merinkangas et al., 2010). Internalizing behaviors, such as depression and anxiety, display lower rates of intervention due to the difficulty with identification in children (Lewinsohn et al., 2003; Splett et al., 2018).

Schools are adopting comprehensive frameworks called multi-tiered systems of support (MTSS) in order to identify each student's SEB needs by utilizing universal screening and teamdriven decision-making. MTSS is a tiered structure of intervention that assists students with both the academic and behavioral needs. Tier 1 involves utilizing evidence-based universal strategies aimed at improving the academics and behavior of every student. Tier 2 involves targeting students with emerging needs and implementing group-based interventions. Tier 3 involves creating intensive intervention plans for individual students who display more complex problems (McIntosh \& Goodman, 2016). Overall, the goal of the MTSS framework is to integrate academic and behavioral interventions into one framework, as integrating interventions together has shown to provide a larger improvement in outcomes (McIntosh \& Goodman, 2016).

An essential part of ensuring that all students with SEB concerns receive intervention is early and reliable assessment to correctly identify those at-risk. Successful interventions can only be implemented if the referral methods used by teachers and staff work to connect students with need to appropriate services (Splett et al., 2018). School-based universal SEB screening is one method of referral that has many benefits, including its utility in identifying all students with SEB needs (Splett et al., 2018). Teachers are key players within a MTSS system as they are often responsible for identifying, referring and helping students acess supports for their SEB needs (Stiffman et al., 2004). Attitudes towards mental health practices are associated with the uptake and implementation of such practices (Brimhall et al., 2016). Further, the level of implementation of evidence based practices is significantly related to program outcomes, including student well-being (Durlak \& DuPree, 2008). Thus, teachers' feelings towards 
addressing students' SEB needs and their implementation practices are important in advancing universal SEB screening.

\section{Effects of Implementation Quality}

Implementation refers to "the process of putting to use or integrating evidence-based interventions within a setting” (Rabin \& Brownson, 2018, p.22). Durlak and Dupre (2008) found that implementation factors were significantly positively related to desired program outcomes for students. Derzon et al. (2005) provided supporting evidence that programs with effective implementation were significantly favored over poorer implementation, as mean effect sizes were shown to be two to three times higher. However, studies have shown that schools struggle to maintain implementation of the evidence-based decision-making necessary for student outcomes to improve (Bartels \& Mortenson, 2006).

Given the relationship between implementation and outcomes, quality implementation is necessary to make impactful differences in students' lives. Even though the relationship is backed by extensive literature, previous implementation efforts have failed to produce meaningful outcomes (Bartels \& Mortenson, 2006). Domitrovich et al. (2008) implementation framework for evidence-based practices in a school setting illustrates that there are multi-faceted influences on implementation quality, which are known as implementation determinants. Implementation determinants are factors that promote or restrict changes at multiple levels(macro, school, \& individual). Macro-level determinants consist of the larger social, political, and economic climate and are often times difficult to adjust. School-level determinants consist of the schools' resources, organizational climate, and administrative leadership. Individual-level determinants consist of the specific traits, attitudes, and competency of implementation providers. Overall, the literature suggests that determinants within the implementation framework work across levels to impact the quality of intervention implementation.

\section{Teachers' Perceptions on Universal Screening}

At the individual-level, an under-explored area is educators' perceptions of screening and intervention and their implementation in their school. Teachers play an instrumental role in the SEB screening process since they often observe students' behaviors and have a direct impact on interventions. However, teachers may not be provided with the necessary tools or trainings required for successfully implementing screening (Cunningham \& Suldo, 2014). Teachers' lack 
of knowledge about mental health and support from school administration provide evidence of a barrier to service for children with specific emotional needs (Reinke et al., 2011). Understanding the importance teachers place on screening and intervention practices and what tools administration provides them with may help to assess how likely a school is to implement such practices.

Research displays that teachers overwhelmingly agree that schools need to be directly involved with maintaining the mental health of their students (Reinke et al., 2011). Although teachers do believe that screening and interventions are necessary, there are still concerns regarding the implementation of these activities and teachers' roles. The perception that screening may not be necessary or is burdensome may lead to poor implementation and invalid outcomes. Ransford and colleagues (2009) examined how educators who reported the highest feelings of burnout and most negative perceptions of supports reported lower quality implementation. This increase of burnout and reported stress examined in an abundance of literature may negatively influence teachers' perceptions of additional screening and intervention duties.

School-level variables that could potentially affect implementation quality include the management of resources at school. Effective leadership in a school system can serve as a catalyst for intervention implementation, as the individual(s) in charge have the ability to promote and enhance attitudes toward the importance of implementing resources for students. Leaders in the school are also able to hold educators accountable for implementation practices, specify roles between the staff, and provide the necessary trainings required for high quality implementation. Assessing teachers' perceptions on how prepared, supportive, and professional the leadership is may indicate how effectively intervention implementation will take place.

\section{Purpose of the Current Study}

Before research can test the hypothesis that these perceptions of SEB screening and intervention impact implementation, measures are needed to reliably and sensitively assess them. The Teacher Perceptions of Screening and Mental Health Practices (TPSMHP) Survey was designed to assess teachers' perceptions of SEB interventions and the school's organizational climate to support implementation of universal screening and evidence-based mental health interventions. The current study represents a first step towards examining the reliability and 
sensitivity of the TPSMHP Survey. Results will help refine the survey and strengthen the validity of future research in this area.

The TMSMHP Survey consists of 110 items in different question formats: Likert scale, multiple choice $\mathrm{Y} / \mathrm{N}$, and fill-in-the-blank. The items consist of questions regarding organization and management in the school, availability of interventions for students with SEB concerns, perceptions about SEB screening, and intervention connections. The survey drew questions from several existing surveys, including the 5Essentials Survey (Bryk et al., 2010), the Mental Health Needs and Practices in Schools Survey (Reinke et al., 2011), Teacher Mental Health Vignette Scale (Green et al., 2018), NEEDS2 Teacher Survey (Marcy, Dineen, McCoach, Chafouleas, \& Briesch, 2018), Physician Belief Scale (McLennan, Jansen-McWilliams, Comer, Gardner, \& Kelleher, 1999), Usage Rating Profile Assessment (URP-A-Chafouleas, Briesch, Neugebauer Riley-Tillman, \& McCoach, 2009), and Social, Emotional, and Behavioral Screening Acceptability (items adapted from Intervention Rating Profile (IRP)-(Martens, Witt, Elliott, \& Darveaux, 1985).

To examine the validity of scales from the TPSMHP survey, this study aimed to answer the following questions: (1) To what extent are the subscale scores of the TPSMHPS survey a reliable measure within the educator population at each participating school?, and (2) Do the subscale scores sensitively detect between school differences? Overall, this study will serve as evidence for or against the use of this survey in future studies of educators' perceptions of screening implementation and intervention services.

\section{Methods}

\section{Participants}

Participants included teachers, administrators, counselors, or other educators from six elementary schools participating in a larger project $(\mathrm{N}=257)$. The majority of respondents were female (78.60\%), White (70.82\%) and not Hispanic/Latinx (78.99\%). There was an even distribution in the number of years each educator has spent in their profession, ranging from less than five years (18.29\%) to over twenty years (18.29\%). Approximatley half (52.91\%) of the educators referred to themselves as being a general or special education teacher. Other professional roles in school included roles such as school administrators, school counsleors, and paraprofessionals. See Table 1 for more demographic characteristics. 
Table 1. Demographic Characteristics of Participating Teachers and Staff $(\mathrm{n}=257)$

\begin{tabular}{|c|c|c|}
\hline Variable & Number of Educators & Percentage of Educators \\
\hline \multicolumn{3}{|l|}{ Gender } \\
\hline Female & 202 & 78.60 \\
\hline Male & 23 & 8.94 \\
\hline Prefer to self-identify & 1 & 0.39 \\
\hline Missing & 31 & 12.06 \\
\hline \multicolumn{3}{|l|}{ Ethnicity } \\
\hline $\begin{array}{l}\text { Hispanic, Latino, or Spanish } \\
\text { origin }\end{array}$ & 23 & 8.95 \\
\hline $\begin{array}{l}\text { Not Hispanic, Latino, or } \\
\text { Spanish origin }\end{array}$ & 203 & 78.99 \\
\hline Missing & 31 & 12.06 \\
\hline \multicolumn{3}{|l|}{ Race } \\
\hline White & 182 & 70.82 \\
\hline Black/African American & 27 & 10.51 \\
\hline $\begin{array}{l}\text { American Indian or Alaskan } \\
\text { Native }\end{array}$ & 1 & 0.39 \\
\hline Two or More Races & 5 & 1.95 \\
\hline Other & 8 & 3.11 \\
\hline Missing & 34 & 13.23 \\
\hline \multicolumn{3}{|l|}{ Number of years in profession } \\
\hline $0-5$ & 47 & 18.29 \\
\hline $6-10$ & 41 & 15.95 \\
\hline $11-15$ & 46 & 17.90 \\
\hline $16-20$ & 40 & 15.56 \\
\hline 21 or more & 48 & 18.67 \\
\hline Missing & 35 & 13.62 \\
\hline \multicolumn{3}{|l|}{ Role in School } \\
\hline General Education Teacher & 96 & 37.35 \\
\hline Special Education & 40 & 15.56 \\
\hline Other & 91 & 35.41 \\
\hline Missing & 30 & 11.67 \\
\hline Total & 257 & \\
\hline
\end{tabular}




\section{Procedures}

The six schools involved in the project were recruited because they were implementing universal screening with the Behavioral Assessment System for Children-Third Edition, Behavioral and Emotional Screening System, Teacher Form (BESS Teacher; Kamphaus \& Reynolds, 2014). The BESS Teacher screener is a psychometrically-sound and well-known measure using teacher's responses to assess a student's behavioral and emotional functioning. The TPSMHPS survey was administered to educators in these schools (Grades K-5) in a school district in the Southeastern United States, via Qualtrics, following approval from the authors' institutional review board. A district employee compiled school district emails for all 437 certified staff in the six participating schools and a link to the electronic survey was distributed to them with IRB-approved recruitment emails. Principals were also asked to email a scripted message containing details of the online survey and asking educators to participate. Responses were monitored and reminder emails were sent to those who had not yet completed the survey. In total, 307 educators accessed the survey, with 261 submitting complete or partially-complete responses. Responses from 4 educators were dropped because they did not respond to any of the items corresponding to the scales for this project. A total of 257 individuals responded to the items used in the current study. See Table 2 for sample sizes of each subscale. To incentivize educators to complete the survey, every tenth participant was notified after their survey window closed that they had received a \$20 Amazon gift card. The data collected were kept confidential via de-identification procedures.

\section{Measures and Variables}

\section{personal acceptability of social, emotional, and behavioral interventions. Personal}

Acceptability of SEB Interventions was assessed by six items measured on a 6-point Likert Scale ( $1=$ strongly disagree, $6=$ strongly agree). These items evaluated the extent to which teachers felt they should be involved in a number of functions, including screening for SEB needs, teaching curriculum on SEB functioning in a classroom, referring children to mental health professionals, implementing behavioral interventions in classrooms, completing behavioral ratings to inform intervention, and monitoring progress of students' SEB functioning.

personal acceptability of screening. This scale included ten items rated on the same 6-point Likert Scale. These items evaluated the extent to which teachers felt screening was an effective and efficient tool in their school. It also asked about how fair and reasonable they perceived 
teachers' role in screening to be. It should be noted that this scale was not administered to all respondents because it was only included if the respondent answered yes to a previous question asking if they participated in screening at their school. If the respondent answered "no", the personal acceptability of screening scale was not subsequently administered. A total of 117 teachers responded to the items on this scale.

acceptability of social, emotional, and behavioral interventions at school. This scale included four items rated on the same 6-point Likert Scale. These items evaluated the extent to which teachers felt they were satisfied with the SEB interventions provided at their school and how beneficial the interventions have been. Interventions examples included in the survey were individual counseling and small group social skills building.

management of resources to implement screening. This scale included six items rated on the same 6-point Likert Scale. These items evaluated how effectively teachers felt school personnel implemented SEB screening and intervention implementation and how sufficient they felt personnel provided resources, trainings, and support.

\section{Data Analyses}

All data analyses were conducted using SPSS (IBM Corp. Released 2019. IBM SPSS Statistics for MacOS, Version 26.0. Armonk, NY: IBM Corp). The four subscales previously described were used for analyses by creating an average score for each respondent on each scale. Average scores for each scale could range from 1 (strongly disagree) to 6 (strongly agree). Means for each subscale are reported for the total sample and each school in Table 2. Internal reliability was calculated for items comprising each of the four subscales using Cronbach's alpha. Alpha values utilized to classify results came from DeVellis (1991; minimally acceptable (0.65), acceptable (0.70) and optimal (0.80)). The second research question, intended to detect between school differences, was answered by conducting ANOVAs on the average scores for each survey scale used in the study. 
Table 2. Total Subscale Means and Variance and by School

\begin{tabular}{|c|c|c|c|c|c|}
\hline Group & Statistic & $\begin{array}{c}\text { Personal } \\
\text { Acceptability of } \\
\text { SEB Interventions }\end{array}$ & $\begin{array}{c}\text { Personal } \\
\text { Acceptability of } \\
\text { Screening }\end{array}$ & $\begin{array}{c}\text { Acceptability of } \\
\text { SEB Interventions } \\
\text { at School }\end{array}$ & $\begin{array}{l}\text { Management of } \\
\text { Resources to } \\
\text { Implement } \\
\text { Screening }\end{array}$ \\
\hline Total & $\begin{array}{l}\mathrm{N} \\
\text { Mean (SD) }\end{array}$ & $\begin{array}{c}244 \\
4.764(1.036) \\
\end{array}$ & $\begin{array}{c}117 \\
4.198(0.753) \\
\end{array}$ & $\begin{array}{c}238 \\
3.666(1.145) \\
\end{array}$ & $\begin{array}{c}245 \\
4.123(0.743) \\
\end{array}$ \\
\hline School 1 & $\begin{array}{l}\mathrm{N} \\
\text { Mean (SD) }\end{array}$ & $\begin{array}{c}25 \\
4.953(0.817) \\
\end{array}$ & $\begin{array}{c}15 \\
4.513(0.571) \\
\end{array}$ & $\begin{array}{c}26 \\
4.010(0.876)\end{array}$ & $\begin{array}{c}26 \\
4.423(0.647) \\
\end{array}$ \\
\hline School 2 & $\begin{array}{l}\mathrm{N} \\
\text { Mean (SD) }\end{array}$ & $\begin{array}{c}31 \\
4.409(1.166) \\
\end{array}$ & $\begin{array}{c}13 \\
4.092(1.067)\end{array}$ & $\begin{array}{c}32 \\
3.391(1.291) \\
\end{array}$ & $\begin{array}{c}32 \\
3.917(0.769) \\
\end{array}$ \\
\hline School 3 & $\begin{array}{l}\mathrm{N} \\
\text { Mean (SD) }\end{array}$ & $\begin{array}{c}38 \\
4.983(0.851) \\
\end{array}$ & $\begin{array}{c}19 \\
4.205(0.702) \\
\end{array}$ & $\begin{array}{c}38 \\
3.210(1.124) \\
\end{array}$ & $\begin{array}{c}40 \\
4.158(0.682)\end{array}$ \\
\hline School 4 & $\begin{array}{l}\mathrm{N} \\
\text { Mean (SD) }\end{array}$ & $\begin{array}{c}51 \\
4.699(1.080) \\
\end{array}$ & $\begin{array}{c}23 \\
4.070(0.904)\end{array}$ & $\begin{array}{c}50 \\
3.465(1.114) \\
\end{array}$ & $\begin{array}{c}52 \\
4.000(0.739) \\
\end{array}$ \\
\hline School 5 & $\begin{array}{l}\mathrm{N} \\
\text { Mean (SD) }\end{array}$ & $\begin{array}{c}40 \\
4.971(0.905) \\
\end{array}$ & $\begin{array}{c}17 \\
4.106(0.711) \\
\end{array}$ & $\begin{array}{c}37 \\
3.899(1.078) \\
\end{array}$ & $\begin{array}{c}39 \\
4.162(0.628) \\
\end{array}$ \\
\hline School 6 & $\begin{array}{l}\mathrm{N} \\
\text { Mean (SD) }\end{array}$ & $\begin{array}{c}58 \\
4.655(1.163) \\
\end{array}$ & $\begin{array}{c}29 \\
4.248(0.602) \\
\end{array}$ & $\begin{array}{c}54 \\
3.505(1.205) \\
\end{array}$ & $\begin{array}{c}55 \\
4.167(0.861) \\
\end{array}$ \\
\hline
\end{tabular}

Note. All items rated on a 6-point Likert Scale

\section{Results}

\section{Research Question One: Internal Reliability and Central Tendency}

Cronbach's alphas were calculated for items in each of the four scales to assess the internal reliability of each scale. As reported in Table 3 below, most scales were shown to be internally consistent, with one scale (Management of Resources to implement screening) in the minimally acceptable range. Overall, the internal reliabilities were averaged to give an overall internal reliability value indicating optimal reliability $(\alpha=0.787)$. Mean scale scores and variances are also reported in Tables 2 and 3 , and indicate average agreement on all subscales.

Table 3. Internal Reliability

\begin{tabular}{lc}
\hline Subscale & Cronbach's Alpha \\
\hline Personal Acceptability of SEB Interventions & 0.913 \\
Personal Acceptability of Screening & 0.815 \\
Acceptability of SEB Interventions at School & 0.803 \\
Management of Resources to implement screening & 0.616 \\
\hline
\end{tabular}




\section{Research Question Two: Inter-School Variability}

Using the mean scores for each participating school for each survey subscale reported in Table 2, one-way ANOVAs were conducted to examine the mean differences between schools. No significant differences were detected between schools for any of the four scales tested (see Table 4). Of the four tests conducted, one scale approached significance, including “Acceptability of SEB Interventions at School." ( $<<0.06)$. The remaining significance values $(p)$ were all greater than 0.1 . In addition, posthoc analyses only revealed non-significant differences between any two schools for each of the subscales.

Table 4. One-Way ANOVAs Between Groups

\begin{tabular}{lccc}
\hline Subscale & Mean Square & F & Significance $(p)$ \\
\hline Personal Acceptability of SEB Interventions & 1.806 & 1.705 & 0.134 \\
Personal Acceptability of Screening & 0.444 & 0.771 & 0.572 \\
Acceptability of SEB Interventions at School & 2.771 & 2.158 & 0.060 \\
Management of Resources to implement screening & 0.942 & 1.726 & 0.129 \\
\hline
\end{tabular}

\section{Discussion}

The goal of this validation study was to provide evidence for the TPSMHP survey as an accurate and reliable method to measure teacher's perceptions of screening and SEB interventions. The study provided validity evidence by assessing internal reliability and variability between schools. Analyses on internal reliability revealed that three of the four subscales had a Cronbach's alpha values of greater than 0.80 , so they were optimally reliable. "Management of Resources to implement screening" was shown to be internally consistent, but, in the minimal range ( $\alpha=0.616)$; this subscale likely had the lowest alpha because questions used in the subscale inquired whether school personnel had sufficient resources and whether they required additional training. It is possible that educators who filled out the survey believed that numerous resources were given, but that additional training outside of what was provided by the research team may assist in improving implementation quality. The average of the six alphas was 0.787, which indicates average to optimal internal reliability. No subscales had to be excluded from the calculation of the overall internal reliability value because the alphas were approximately consistent across the four individual subscales.

ANOVAs were run to examine the sensitivity of the survey and its ability to detect between school differences. Significant differences were expected between the schools given 
differences in organizational climate, administration experience, and other system factors. No significant differences were observed between schools, indicating that the survey may not be able to detect such differences. Because the second hypothesis was not supported, this survey in its current state may not be a useful tool in future research with the goal of assessing the impact of teachers' perceptions of SEB screening and interventions on actual outcomes. Such an analysis would require detecting a range of school-level perceptions and thus future research is needed to further test and develop the TPSMHP's sensitivity. Between-school differences may have not been detected given all schools were in the same school district and with similar MTSS frameworks.

\section{Limitations}

The focus of this study was to provide evidence for the use of this survey as a valid and reliable measure of teachers' perceptions of SEB screening and practices. Collaboration with only six schools in a small, central Florida county may lead to a small sample size, so data and results may not be generalizable to the entire population. The schools have also been used before, so they have a relationship with the researchers; this may lead to response bias, as teachers may feel that they should give answers that are acceptable.

There was also a significant number of teachers who failed to respond to the survey, so those that did answer the survey completely may have strong opinions for or against SEB screening and practices. The subscale "Personal Acceptability of Screening" only had a sample size of 117, indicating that 192 answers were missing for the questions in this subscale; this could influence how generalizable this data is, as responses from the missing 192 people could have provided different statistics on the subscale reliability and inter-school variability.

\section{Conclusion}

Overall, this study serves to address the need for a measure of teachers' perspective of universal SEB screening and interventions. In order for screening and intervention to achieve intended results for all students, they must be implemented with quality. The TPSMHP survey is designed to bring teachers' perspective to light given they are an essential part of ensuring SEB concerns are efficiently and effectively addressed for all students. Although the survey was shown to be internally consistent in the current study, lack of inter-school variability suggests further research is needed. Developers should consider additional between school analyses to consider other differencs that may exist, as well as item-level analyses to determine what, if any, 
changes to the subscales may be needed. This survey is needed in future work to examine the influence of teachers' perceptions on screening and intervention outcomes. If influential, interventions to address these perceptions could be designed and tested. Thus, results of this study should encourage continued survey testing and development, as well as implementation work to improve the outcomes of SEB screening and intervention.

\section{References}

Bartels, S. M., \& Mortenson, B. P. (2006). Enhancing adherence to a problem-solving model for middleschool pre-referral teams: A performance feedback and checklist approach. Journal of Applied School Psychology, 22(1), 109-123. https://doi.org/10.1300/J370v22n01_06

Brimhall, K. C., Fenwick, K., Farahnak, L. R., Hurlburt, M. S., Roesch, S. C., \& Aarons, G. A. (2016). Leadership, organizational climate, and perceived burden of evidence-based practice in mental health services. Administration and Policy in Mental Health and Mental Health Services Research, 43(5), 629-639. https://doi.org/10.1007/s10488-015-0670-9

Cunningham, J. M., \& Suldo, S. M. (2014). Accuracy of teachers in identifying elementary school students who report at-risk levels of anxiety and depression. School Mental Health, 6(4), 237250. https://doi.org/10.1007/s12310-014-9125-9

Darney, D., Reinke, W. M., Herman, K. C., Stormont, M., \& Ialongo, N. S. (2013). Children with cooccurring academic and behavior problems in first grade: Distal outcomes in twelfth grade. Journal of School Psychology, 51(1), 117-128. https://doi.org/10.1016/j.jsp.2012.09.005

Derzon, J. H., Sale, E., Springer, J. F., \& Brounstein, P. (2005). Estimating intervention effectiveness: Synthetic projection of field evaluation results. Journal of Primary Prevention, 26(4), 321-343. https://doi.org/10.1007/s10935-005-5391-5

DeVellis, R. F. (1991). Guidelines in scale development. Scale Development: Theory and Applications. Newbury Park, CA: Sage Publications.

Domitrovich, C. E., Bradshaw, C. P., Poduska, J. M., Hoagwood, K., Buckley, J. A., Olin, S., ... \& Ialongo, N. S. (2008). Maximizing the implementation quality of evidence-based preventive interventions in schools: A conceptual framework. Advances in School Mental Health Promotion, 1(3), 6-28. https://doi.org/10.1080/1754730X.2008.9715730

Durlak, J. A., \& DuPre, E. P. (2008). Implementation matters: A review of research on the influence of implementation on program outcomes and the factors affecting implementation. American Journal of Community Psychology, 41(3-4), 327-350. https://doi.org/10.1007/s10464-008-9165-0

Forness, S. R., Freeman, S. F. N., Paparella, T., Kauffman, J. M., \& Walker, H. M. (2012). Special education implications of point and cumulative prevalence for children with emotional or behavioral disorders. Journal of Emotional and Behavioral Disorders, 20(1), 4-18. https://doi.org/10.1177/1063426611401624 
Kamphaus, R. W., Reynolds, C. R., Hatcher, N. M., \& Kim, S. (2014). Treatment planning and evaluation with the Behavior Assessment System for Children (BASC). In M.E. Maruish (Ed.), The use of psychological testing for treatment and planning and outcome assessment, volume 2: Instruments for children and adolescents. (3rd ed., pp. 331-354). Mahwah, NJ: Lawrence Erlbaum Associates, Inc.

Lewinsohn, P. M., Petit, J. W., Joiner Jr, T. E., \& Seeley, J. R. (2003). The symptomatic expression of major depressive disorder in adolescents and young adults. Journal of Abnormal Psychology, 112(2), 244. https://doi.org/10.1037/0021-843X.112.2.244

McIntosh, K., \& Goodman, S. (2016). Integrated multi-tiered systems of support: Blending RTI and PBIS. Guilford Publications.

Merikangas, K. R., He, J. P., Burstein, M., Swanson, S. A., Avenevoli, S., Cui, L., ... \& Swendsen, J. (2010). Lifetime prevalence of mental disorders in US adolescents: results from the National Comorbidity Survey Replication-Adolescent Supplement (NCS-A). Journal of the American Academy of Child \& Adolescent Psychiatry, 49(10), 980-989. https://doi.org/10.1016/j.jaac.2010.05.017

Merikangas, K. R., He, J. P., Burstein, M., Swendsen, J., Avenevoli, S., Case, B., ... \& Olfson, M. (2011). Service utilization for lifetime mental disorders in US adolescents: results of the National Comorbidity Survey-Adolescent Supplement (NCS-A). Journal of the American Academy of Child \& Adolescent Psychiatry, 50(1), 32-45. https://doi.org/10.1016/j.jaac.2010.10.006

Rabin, B.A., \& Brownson, R.C. (2018). Terminology for dissemination \& implementation research. In R.C. Brownson, G.A. Coldite, \& E.K. Procotors (Eds.), Dissemination \& implementation research in health: Translating science to practice (pp. 19-46). New York: Oxford University Press.

Ransford, C. R., Greenberg, M. T., Domitrovich, C. E., Small, M., \& Jacobson, L. (2009). The role of teachers' psychological experiences and perceptions of curriculum supports on the implementation of a social and emotional learning curriculum. School Psychology Review, 38(4), 510-532. Retrieved July $1^{\text {st }}$, 2020, from https://login.lp.hscl.ufl.edu/login?url=https://search.proquest.com/docview/219656424?accountid $=10920$

Reinke, W. M., Stormont, M., Herman, K. C., Puri, R., \& Goel, N. (2011). Supporting children's mental health in schools: Teacher perceptions of needs, roles, and barriers. School Psychology Quarterly, 26(1), 1-13. https://doi.org/10.1037/a0022714

Splett, J. W., Trainor, K., Raborn, A., Halliday-Boykins, C., Dongo, M., Garzona, M., \& Weist, M. D. (2018). Comparison of universal mental health screening to students already receiving intervention in a multitiered system of support. Behavioral Disorders (special issue), 43(8), 344356. https://doi.org/10.1177/0198742918761339 